\title{
Os sentidos apontando para uma nova transformação, de Hélio Oiticica
}

\author{
Tradução do inglês: \\ Luiz Guilherme Vergara * \\ Universidade Federal Fluminense, Brasil \\ Kelly Santos ** \\ Universidade Federal Fluminense, Brasil
}

https://doi.org/10.22409/poiesis.v20i34.38529

RESUMO: Este texto foi escrito para o Simpósio de "arte tátil" realizado este ano (12 de julho de 1969) na Universidade Estadual da Califórnia em Long Beach Lygia Clark e eu fomos convidados. O texto pretende mostrar e definir as possíveis relações com o sujeito e, também, as profundas diferenças, indicando os pontos em comum entre os trabalhos de ambos e a procura de um novo exercício de comunicação que, ao invés de uma busca por "invenções formais", sirva como uma verdadeira linha de pensamento para lidar com os desafios da atualidade.

PALAVRAS-CHAVE: Oiticica; arte brasileira; arte contemporânea; Studio International

\footnotetext{
* Luiz Guilherme Vergara é professor associado do Departamento de Arte e do Programa de Pós-Graduação em Estudos Contemporâneos das Artes da UFF. É cofundador do Instituto MESA e coeditor da Revista MESA. E-mail: luizguivergara@gmail.com. Orcid: https://orcid.org/0000-0002-5311-5181

${ }^{* *}$ Kelly Santos é mestranda do Programa de Pós-Graduação em Estudos Contemporâneos das Artes da UFF. E-mail: kessantos@gmail.com. Orcid: https://orcid.org/0000-0003-1487-1694
} 
N. do E.: Este ensaio, inédito em português, foi escrito pelo artista na cidade de Londres, entre os dias 18 e 25 de junho de 1969. Produzido para a revista britânica Studio International, mas não impresso à época, é retomado pela revista americana ARTMargins (The MIT Press), v. 7, n. 2, p. 129-135, 2018, editada por Luke Skrebowski, 2018. Os editores agradecem aos membros do Grupo de Pesquisa: Interfluxos Contemporâneos Arte e Sociedade da UFF e, em especiais, à Paula Braga por sua colaboração. Agradecemos igualmente a Cesar Oiticica Filho e ao Projeto Hélio Oiticica, que, gentilmente, autorizaram a tradução deste ensaio e sua publicação na revista Poiésis. 


\section{Os sentidos apontando para uma nova transformação, de Hélio Oiticica}

O processo de mudança do principal foco estético das chamadas artes "visuais" e a consequente introdução dos demais sentidos não se atém ou se baseia em um ponto de vista puramente esteticista, isto é muito mais profundo; é um processo que, em última análise, correlaciona e sugere uma possibilidade inédita de comportamento[al] não condicionado: a consciência do comportamento enquanto chave fundamental para a evolução dos assim-chamados ${ }^{1}$ processos artísticos $\rightarrow$ a consciência de uma totalidade, da relação indivíduo-mundo tal como uma ação total, onde a ideia de valor não está pautada por um "foco" específico: o acontecimento esteticista outrora tomado como "objetivo-foco": os conflitos tendem a ser absorvidos pelo próprio comportamento, apartados do foco visual superintelectualista, demasiadamente submisso a essa relação de "valor-foco". O apelo aos sentidos, que pode ser uma concentração "multifocal", se torna importante como um meio para a assimilação comportamental: olfato- 
visão-paladar-audição e tato se misturam e se tornam aquilo que Merleau-Ponty chamara de "simbólica geral do corpo", onde se estabelecem todas as relações entre os sentidos em um contexto humano, tal como um "corpo" de significações e não um somatório de significações apreendidas por canais específicos: a assimilação e a ação não podem estar isoladas e, assim, a concepção analítica dos sentidos se torna também uma metáfora para expressar a complexidade do comportamento humano. Contudo, emergimos da racionalidade pura, "relações objetais" 2 dos problemas-arte, de condições estabelecidas para uma "ação estética" extremamente desenvolvida durante tantos anos, para uma ideia de mundo humano-integral, para a crença na ação comportamental como uma força criativa e não "passiva" ou "de fundo": a dissolução da "arte" nisto não é também uma "dissolução objetal", mas o fluir de ideias específicas concentradas $^{3}$, problema fundamental ideias criativas, na manifestação da vida até onde for o alcance do infinito campo do comportamento humano, como uma construção de significações, corpos simbólicos de relações tão ricos em si mesmos e reinformados, então, por este corpo agora significativo ${ }^{4}$, propagando de modo cres- cente desde a sua prévia posição sublima$\mathrm{da}$, desde o seu antecedente "background", que é o mundo do comportamento[al].

Com efeito, a arte no passado sempre tentou de maneira metafórica criar e, de fato, criou, um novo nível de relações significativas: um mundo em si mesmo que poderia ser sentido, vivido e proposto como uma estrutura, uma estrutura criativa, oposta ao mundo objetal, como um "modelo" de verdade sintética e não corrompida em si. Frequentemente, então, na maioria das vezes, eu diria que o artista-criador seria o atorcriador, o gerador sublime de forças criativas e o receptáculo delas, ele próprio os pólos do mundo significativo estrutural proposto por suas criações. As grandes diferenças em uma nova posição seriam, considerando que as ligações anteriores eram totalidades metafórico-estruturais impostas ao mundo comportamental, os elos atuais que tendem a se desenvolver a partir dele e após um longo processo de dissolução dos "atos vivos humanos" $\rightarrow$ o destino das ações humanas vivas se encontra livre de esforços sublimatórios intermediários, conflitos transcendentais ou objetivos ideais. 
THE SZUSES DOTKRTG TOUARDS A HEA TRAHSFORYATICK

Eo110 01t10102

The procees of abifting the eain aeatbetie foeve avay fros the so called "vieual" arte and the introduetion, then, of the otzer sonses, should not be concentrated or looked at fron a purely aesthotielet point of viow; it io much zore profound; it 10 a process whieb, in 1 ts ultinate eoneo, relates and proposes a now unoonelitioned behaviour posalbillty : the conselousness of behaviour as a fundasental koy to the evolution of the so-oelled art processes $\rightarrow$ the coneciousnese of a totality, of the relation Individual-world as a whole sction, where tho 1 cea of value 10 not only related to a speirle 'focus', the aesthotielst ovent taken forzor $2 \mathrm{y}$ al the 'foeps Q021. : tho conr11ete tond to be abeorbed into bohaviour 1teelf, avay fros the ouper intelloctualiot vioual foevs, too eubsitted to that 'foeus-valuo' relation. The appeal to the soveos, which oan be a tult1-foeel' concontration, becores 1mportant as a way tovards thlo bobevioural absorption ; esoll-a1gat-tasto-hearing and touch single and are what Kerleau-Ponty once cullod the "body'o general eysbolice", where all sonse roLations are establiohed in a buman context, as a "body" of significatione and not a sun of of gnificatione apprehenced by opecific channols i the approhonnion and the action cannot be 1oolated, and the analytical 1 dea of the censee becoseca netaphort too to express tbe complexity of buzan bohaviour. But, wo onorgo froa purely rational, 'objectal rolations' of art-probless, of establisbed conditions for an "aesthet10 action" so zuch doveloped during so zany years, into the ldea of a wolo buean world, Into the trust in bobavioural aetion as a contive force and not a 'pessive' or 'beckground' one $t$ the dissolution of "art" Into it is not also an 'objectal diesolution' but a fowing of ooscentrated oposifio 1doas, fundanental probles-ereat1vo 1doas, Into 1sfo ranifootation we far ao tho infinito area of ruman behaviour is concerned, as a bullding up of algalfications, syabolic bodies of rolations, wo riob in thonselves and rosnforeed then, by this nou elgnificative body sproad-growlng from 1te foraer aublimato poeltion, into ite formor Background', whlob is the bobaviour vorld.

Of course peet art always tried in a eetaphorical way to croate, and did create, a now lovel of eigniflcative relations i a world in 1 teele could be folt and lived and proposed as an strueture, a creative structure, opposite the objectal world, as a "zodol" of synthetic truth, uncorrupted in 1tself. Orton then, eost2y I should aay, the artist-ereator would be the actor-ereator, the subliss generator of ereative forces and the reeipient of then, he hisself the poles of the atructural algnifleativ world propoeed by blo oreations. The great difforences in a new poestion would be 
Como um estágio evolutivo desses "processos de atos vivos" podemos destacar a dissolução das antigas formas de arte, pintura, escultura etc., para o "objeto" híbrido. Entretanto, durante toda a evolução da arte moderna o conflito entre a ideia de um "objeto-arte" e de uma "anti-arte" foi se dirigindo para um impasse. A anti-arte, levada a formas dramáticas recentemente, ao "limite da experiência", demanda agora uma radicalização definitiva. Muitas iniciativas estagnaram ou retrocederam em relação a este impasse: a urgência de um novo campo de considerações é sentida - a concentração no próprio processo é o começo de uma nova luz que gradativamente invade e gera estas considerações: eu chamo isso, nos meus trabalhos experimentais, um crecomportamento; não se trata simplesmente de um "comportamento criativo", embora possa ser, mas algo bem mais amplificado; não é um objeto-criação através do comportamento, tampouco a transformação dos atos vivos em criativos, o que seria uma noção simplista ${ }^{5}$ : em tal caso as circunstâncias se tornariam meras Utopias distantes, mas, se de dentro do comportamento condicionado os elementos começam a crescer como necessidades, como germes que irromperam do centro dos próprios conflitos, e informam o comportamento de uma nova maneira aberta, completamente livre com os atos vividos individuais: o processo que conduz e informa para o próprio centro do conflito de comportamento[al] e se abre para transformações surpreendentes $\rightarrow$ não para se contentar com o esforço em "alcançar um modelo" de vida, mas para viver em uma consciência contínua de tais conflitos, o que poderia ser o único caminho para que tal processo de transformação ocorra.

O apelo ao auxílio do sistema sensorial vive para além do objetal: a consciência do "do corpo-simbólico" como uma totalidade imediatamente "a mão" é algo muito mais correlacionado ao comportamento em si do que às relações objetais; uma relação mais rica que aumenta as possibilidadesprobabilidades vividas na consciência imediata do "corpo totalidade" em ação; quando Lygia Clark, por exemplo, propõe sua experiência de "nostalgia do corpo", ela está propondo, através de simples atos sensoriais, a possibilidade de uma consciência re-informada do corpo como algo vivo, como se descoberto pela primeira vez, assim propondo uma nova relação entre o autoconhecimento e o conhecimento dos outros. Aqui podemos vislumbrar a possibilidade de 
um processo ao invés de uma estruturaobjeto que impõe relações metafóricas; poderia ser um sentido vivo de descoberta, um processo em si e não um processo para um objetivo. Os sentidos então, correlacionados e agindo sobre os corpos-simbólicos, podem ser considerados como meios essenciais para a apreensão desse processo. O comportamento reside apenas nele mesmo e reformula continuamente tais simbólicos (como Merleau-Ponty demonstra, o comportamento, neste caso, é significação em si mesmo e não está à procura de um significado específico).

Uma vez que as "distâncias" entre os objetivos estéticos ideais são abolidas ou transformadas em crecomportamento, na consciência contínua de um processo vivo, os conflitos tendem a ser resolvidos ou assumirem níveis superiores. Em minha evolução, cheguei ao que chamo de crelazer. Para mim, o clássico conflito alienação-lazer, que produz a ideia de lazer alienado, tal como ele é representado no mundo ocidental moderno, seria contestado como uma consequência direta da absorção dos processos-artísticos pelos processos-vivos. Crelazer é o lazer não repressivo, em oposição ao desviado pensamento opressivo de lazer: uma nova maneira não condicionada de combater formas sistemáticas opressivas de vida. Sua prática, prática-aberta, é um modo de se apossar de um processo, um processo criativo sinergético ${ }^{6}$, em que a apreensão-sentidos é uma apreensãocorporal que gera a ação-comportamento num processo orgânico total.

O trabalho de Lygia Clark e o meu, em nossas evoluções, trazem esses dois pontos em comum, e não apenas entre si, mas também imbricados nos esforços da vanguarda que caracterizaram [a] cena-artística brasileira na última década, afirmando com as influências universalistas constantes de Mario Pedrosa; através da "Teoria do Não Objeto" de Ferreira Gullar (1959); no sentido da ideia de "probjeto" (Rogerio Duarte) (1968); nas recentes e fascinantes experiências de Lygia Pape (eu tenho [escrevi] um artigo especial sobre ela); das atividades do Grupo Neoconcreto (1959-60); no decorrer de todas as participações-públicas levando à recente síntese da Tropicália - e nisso se diferem das ideias tais como "happenings" ou "eventos" e caracterizam de modos totalmente independentes os movimentos do Rio e de S. Paulo. Não vou aqui fazer uma relação completa de tais experi- 
mentos - eles são vastos; as ideias diversas. Prefiro me ater aos meus próprios experimentos e às últimas ideias e conquistas de Lygia Clark. Podemos ter aqui, então, exemplos diretos e discussões possíveis.

Como eu estava dizendo, os esforços gerais nessas ideias atuais ativam uma importante ideia principal: a verificação permanente do conflito entre o objeto, tal como ele aparece em suas formas variadas (obra de arte, objeto funcional etc.), e as relações sujeitoobjeto: este conflito é conhecido desde a formulação do "não-objeto" de Gullar, em 1959, durante as atividades do Grupo Neoconcreto. O problema detectado se revelou, então, muito complexo e ainda se mantém como linha mestra de pensamento para esses artistas. As relações com todos os movimentos internacionais são óbvias - e as diferenças também. A maior delas estaria no modo como este conflito principal do sujeito-objeto levou a uma dissolução da ideia de arte-objeto para relações comportamentais diretas e a reversão das antigas relações objetais: as estruturas antigas das arte-formas, que foram concebidas para serem estruturas totais condicionantes de comportamento das estruturas-totais, se dissolveram nessas evoluções e passaram a propor o inverso disto, que seria o comportamento definido como estrutura-total, gerando os elementos que não são estruturas de arte total (aberto-aberto), mas o fluxo vivo da experiência do destino humano. Esse processo é sem fim e nenhuma oferta de solução rápida deve ser feita. É um processo dentro de um processo. O que realmente poderia ser formulado e admitido é a insuficiência7 da arte-objeto como tal. A experiência desse processo pode gerar qualquer forma comunicante que for, mas nunca o conciliador arte-objeto se vinculou à antiga "distante" relação objetal. Se a comunicação não for direcionada para uma relação comportamental, então, ela é velha, por mais nova que a forma possa ser. Uma relação que apontasse para um ideal estático, um modelo sublime, permanece sendo uma relação transcendental arcaica, que resistiu através da arte ocidental durante muito tempo. O mesmo pode ser aplicado aos processos da anti-arte, principalmente porque eles podem dissimular sob sua aparência uma atitude antiquada: é inútil ter "participação" ou "proposições", caso não estejam pautadas por uma mudança completa na relação objetal; o mesmo com o que poderia ser chamado de "participação sensorial". 
Recentemente, uma nova demanda e decisões importantes me acometeram: nas experiências que proponho, como, por exemplo, a prática do crelazer. A impossibilidade de "expor" objetos como parte dessa ideia, em galerias ou museus, se tornou evidente: tive um vislumbre sobre isso com a experiência do Whitechapel em Londres, entre fevereiro-abril de 1969. Para mim, foi mais uma experiência do que uma exposição (eu propus coisas ao invés de exibi-las). Mas toda a evolução que apresentei lá conduz a essa condição: a impossibilidade dos experimentos em galerias ou museus - suas áreas externas ainda poderiam ser mantidas dependendo das correlações e razões para elas: posso mencionar alguns dos experimentos da Exploding Galaxy em Londres, Amsterdã, ou Paris, como visando algo análogo; no Rio, a Apocalipopótese, em agosto de 1968. A sala de exposição sempre se refere a uma ideia velha de "exibir objetos", de "objeto representação"; então, por que insistir em uma forma velha quando um novo mundo experimental clama, e com urgência, por formas completamente novas de comunicação. Estamos no começo de uma nova linguagem, um novo mundo de experiências de comunicação, propondo uma revolução completa para um levante individual-social. A ideia de comunidadescélulas ou de comunidades experimentais veio a mim em paralelo às amplamente divulgadas coletividades, tal como a construção de sítios coletivos ou lugares de habitar: nos primeiros, o crelazer privado das células-grupo estaria envolvido em um projeto que tenho em mente há bastante tempo: o Barracão: posteriormente, a ideia de meio ambiente estaria na gênese da criação de arquiteturas e jardins reais, sítios inventados que poderiam ter um novo sentido, longe das experiências "integrativas", que para mim ainda possuem conotações objetais. Os grandes experimentos grupais coletivos $^{8}$ deveriam ter a possibilidade de contar com lugares de habitar grupal, onde os experimentos não estariam vinculados à ideia de um "experimento-show". Em vez disso, deveriam se concentrar em uma experiência propositora de crescimentointerno: propondo propor, o que poderia conduzir a caminhos fascinantes; ou, igualmente importante, construir novas possibilidades de caminhar através de lugares (no meu trabalho, ideias sobre isso vieram desde 1960, principalmente com os "núcleos" e "penetráveis" e projetos para construções de ambientes - eles sofreram grandes mudanças ao longo desses anos; 
eu proponho muito mais um "ambiente aberto vivo" do que qualquer coisa que seja objetal, que poderia ainda manter velhas ideias formais).

As experiências comunais internas são as mais complexas e fascinantes: a ideia de desenvolver relações-experimentos grupaisexpansivos pode criar células expansivas para futuros experimentos; elas podem ser centros, pequenos centros, com certeza, de experiências-vivas condensadas e fechadas, onde a demanda por um novo tipo de relacionamento social seria essencial; o conflito, portanto, poderia e deveria ser transformado em uma dinâmica permanente: o núcleo crelazer absorvendo e transformando os bombardeios do comportamento destrutivo: isso só pode ser devidamente experimentado quando posto inteiramente em prática.

As experiências mais recentes de Lygia Clark a conduziram para proposições fascinantes, e ela descobriu que certamente a sua comunicação terá que ser mais uma introdução a uma prática que chama celular: de pessoa a pessoa, corpora; um diálogo improvisado que pode se expandir por toda uma cadeia criando como que um conjunto biológico ou o que eu chamaria de creprática. A ideia de criar tais correlações está acima de uma participação simplista como manipulação de objetos; há a procura do que se poderia chamar de ritual biológico, onde as relações interpessoais se enriqueceriam e estabeleceriam uma comunicação de crescimento num nível aberto. Eu digo aqui nível aberto, porque ele não se relaciona a uma comunicação objetal, de sujeitoobjeto, mas a uma prática interpessoal que conduz a uma comunicação real aberta: o contato eu e você, rápido, breve como o próprio ato. Nenhum proveito interesseiro, corrupto, deve ser esperado - as observações de "isto não é nada" ou "de que se trata"? etc. devem ser esperadas; a introdução como iniciação é necessária ${ }^{9}$ (eu posso dizer que desde que introduzi as capas $\mathrm{Pa}$ rangolé, no início de 64 , os meios e modos de introdução eram muito mais primários e difíceis: eu decidi que a dança e o ritmo seriam ideais para isso, mas isso não ajudou muito; agora me parece que a mente coletiva está mais pronta para ser introduzida àquelas práticas do que então - práticas abertas, digamos - aquelas ideias se transformam em aspirações vivas para uma escala coletiva, mais do que detalhes perdidos em um todo). 
Os elementos usados em todas essas experiências baseadas num processo, um processo-vital ${ }^{10}$, são eles mesmos partes dele e não objetos isolados: são ordens num todo..."11 No Barracão que estou projetando os elementos se unirão, improvisados, e crescerão em um processo-ostra; os elementos de Lygia Clark se comunicam em um processocadeia etc. Então, de repente, a alegria de "fazer coisas" pode ser importante, não como gratuidades espúrias a serem consumidas pela sociedade afluente ou pela "cultura" opressiva, e elas não estão submetidas ao privilégio do artista em seu invento, mas grupalmente ou coletivamente abordados. Eles podem ser diretamente uma construção da vida cotidiana, uma célula ou uma semente para viver sem repressões. Todas as tolices das "inovações da arte", do comércio intelectual, do jogo cultural opressor, são superadas e eliminadas por essa realidade mais forte: uma esperança e uma nova luz podem brilhar através dela; a improvisação e os processos criativos acabam por realizar seus destinos com uma nova e poderosa razão para existir.

\section{Notas}

1 N. do T.: Ressalta-se ao longo deste texto uma característica "literária" de Hélio Oiticica no uso do traço de união (hífen) investido de semântica como junção poética preenchendo o elo entre duas palavras por um elemento gráfico que ultrapassa a linguagem escrita para uma confluência gráfica. Exemplo: "_é a total incorporação. É a incorporação do corpo na obra e da obra no corpo... eu chamo in traço de UNIÃO, corporação". (CARDOSO, Ivan. Ivanpirismo p. 68-69). Citação apresentada por Cesar Oiticica Filho em seu texto "A arte supra-sensorial do Yoga." Da mesma forma, podese reconhecer também o uso recorrente das setas " $\rightarrow$ " tornando o texto como uma geopoética de atenção, sinalização e caminho. Um aprofundamento maior é também reconhecido como possível apropriação ou parte da alfabetização do Hélio junto ao seu avô José Oiticica, que elaborou uma gramática com uso de setas, círculos e outras formas de sobrepor a escrita com um dispositivo gráfico visual, mais uma vez territorializando o texto como uma geopoética entre leituracaminho. (Depoimentos da Vera Oiticica, tia do Hélio Oiticica, em conversas sobre a gramática Oiticica com Luiz Guilherme Vergara nos anos 1990.)

2 No uso fora do padrão de Oiticica do termo "objetal", o sufixo "-al" significa "relacionado com; do tipo de" um objeto, em vez de como-objeto.

${ }^{3}$ N. do T.: Observou-se no documento original do Hélio Oiticica (datilografado, p. 1, em inglês) um desacordo com o documento do MIT (ARTMargins). Assim, no documento original: "the dissolution of art into it is not also 'an objectal dissolution' but a fowing of concen 
trated specific ideas" [...] Na edição da ARTMargins, o verbo "fowing" está como "forming" of concentrated specific ideas. Ressalte-se a diferença de sentido entre "fowing" como "temendo" e "forming" - formando.

Paula Braga sugere "flowing", sendo um verbo bastante usado pelo artista. Assim, Oiticica teria cometido um erro de datilografia esquecendo o "l" de "flowing". Texto encontrado no link: https: / /legacyssl.icnetworks.org/extranet/enciclopedia//ho/detalhe/docs/ds p_imagem.cfm?name $=$ anexo $/ 0486.69 \% 20$ normal\%20p01 \%20-\%20567.gif. (último acesso em 28 de outubro de 2018). Um outro link encontra-se uma versão datilografada com correções a mão do artista sobre o texto, também com "flowing”: https://legacyssl.icnetworks .org/extranet/enciclopedia//ho/detalhe/docs/dsp_ima gem.cfm?name=anexo/0486.69\%20normal\%2004\%20\%20569.gif (último acesso em 28 de outubro de 2018).

4, 5 Oiticica usa aqui uma forma adjetival rara "significativo", no sentido de "ser um símbolo ou signo de algo; tendo um significado".

6 N. do T.: Na tradução do inglês de "sympathetic creative process", optamos por "processos criativos sinergéticos".

7 O uso por Oiticica do termo “insuficiência” não está gramaticalmente correto, uma vez que nomes de origem latina convencionalmente tomam o prefixo "in-" em inglês. Entretanto, além do sentido de "ausência de", o prefixo "un-" carrega o sentido de "o inverso de" como também o de "ausência de", a qual "in-" não tem e, portanto, serve aqui como um intensificador.

8 Assim como em "objetal", o sufixo "-al" em "grupal" significa "relacionado a; do tipo de" um grupo, ao invés de grupo. Também é possivelmente uma construção portmanteau, fundindo os sentidos de "grupo" e "comunal".

9 N. do T.: Utilizamos trecho traduzido pelo próprio artista e publicado como Carta Hélio Oiticica para Lygia Clark. Londres, 27/6/1969. In FIGUEREDO, Luciano (Org.). Lygia Clark - Helio Oiticica: Cartas 1964-74. Rio de Janeiro: Editora UFRJ, 1998, p. 121.

10, 11 Na tradução da ARTMargins não consta "processovital”. Apenas na tradução feita na carta do Hélio Oiticica para Lygia Clark, conforme citado na nota acima.

N. do E.: A imagem à p. 17 é um fac-símile de uma das versões/reelaborações de Hélio Oiticica para o texto aqui traduzido.

Hélio Oiticica, Os sentidos apontando para uma nova transformação. 